\title{
Comparison of Clinical and Functional Results after Arthroscopic Bankart Repair with the All-Soft Suture Anchor and the Conventional Metal Anchor
}

\author{
Mehmet ARICAN 國, Yalçın TURHAN îj ${ }^{1}$
}

\begin{abstract}
Aim: To compare the clinical results after arthroscopic bankart repair with all-soft suture anchor and conventional metal anchor in physically active patients with traumatic anterior shoulder instability.

Material and Methods: A total of 32 patients who met eligibility criteria were included between 2016 and 2017 years, for arthroscopic bankart repair in a single orthopedic department. The patients were examined into 2 groups as 17 underwent repair with $1.8 \mathrm{~mm}$ all-suture anchor with 2 (5 metric) Hi-Fi ${ }^{\circledR}$ sutures (Y-knot ${ }^{\circledR}$ flex, Conmed, USA) (group 1), and 15 underwent repair with conventional titanium $3.5 \mathrm{~mm}$ Suture Anchors with two preloaded ultrabraid sutures (TWINFIX, Smith \& Nephew) (group 2). Clinical and functional outcomes were assessed pretreatment, and final follow-up using the American shoulder and Elbow surgeons (ASES) score and the ROWE score.

Results: The mean ASES score increased significantly in group 1 from $35.62 \pm 8.46$ to $88.86 \pm 6.23$ ( $p=0.0001)$ and had increased significantly in group 2 from $41.15 \pm 14.51$ to $91.15 \pm 7.54(\mathrm{p}=0.0001)$. The mean ROWE score had increased significantly in group 1 from $48.82 \pm 11.25$ to $85.00 \pm 10.00(p=0.0001)$ and had significantly increased in group 2 from $45.67 \pm 9.61$ to $87.67 \pm 10.15$ ( $\mathrm{p}=0.0001$ ). There was no significant difference between the mean ASES scores of group 1 and group 2 ( $\mathrm{p}=0.192, \mathrm{p}=0.353)$, and also no significant difference between the mean ROWE scores of group 1 and group 2 ( $\mathrm{p}=0.404, \mathrm{p}=0.461)$ at pretreatment and final follow-up respectively.
\end{abstract}

Conclusion: Arthroscopic bankart repair with an all-soft suture anchor demonstrated comparable clinical and functional results as the conventional metal suture anchor at short term follow-up.

Keywords: Shoulder joint; arthroscopic surgical procedure.

Amaç: Travmatik anterior omuz instabilitesi olan fiziksel olarak aktif hastalarda tüm yumuşak sütür ankor ve konvansiyonel metal ankor ile artroskopik bankart tamirinin klinik ve fonksiyonel sonuçlarının kıyaslanması amaçlanmıştır.

Gereç ve Yöntemler: 2016-2017 yılları arasında, tek merkezde artroskopik bankart tamiri yapılan ve dahil edilme kriterlerimize uyan 32 hasta değerlendirildi. 17 hastaya $1.8 \mathrm{~mm}$ (Y-knot ${ }^{\circledR}$ flex, Conmed, USA) tüm yumuşak sütür ankor (grup 1) ve 15 hastaya ise $3.5 \mathrm{~mm}$ (TWINFIX, Smith \& Nephew) konvansiyonel metal ankor (grup 2) uyguland1. Klinik ve fonksiyonel sonuçlar tedaviden hemen önce ve son takipte Amerikan omuz ve Dirsek cerrahları (ASES) skoru ve ROWE skoru ile değerlendirildi.

Bulgular: Ortalama ASES skoru grup 1'de 35.62 \pm 8.46 'dan $88.86 \pm 6.23$ 'e ( $\mathrm{p}=0.0001$ ) ve grup 2'de ise $41.15 \pm 14.51$ 'den

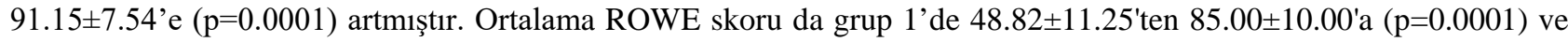
grup 2'de ise $45.67 \pm 9.61$ 'den $87.67 \pm 10.15$ 'e ( $\mathrm{p}=0.0001$ ) yükseldi. Grup 1 ve grup 2'nin tedavi öncesi ve son takibinde ortalama ASES ve ROWE skorlarında fark yoktur ( $p=0.192$, $p=0.353$ ve $p=0.404, p=0.461)$.

Sonuç: Tüm yumuşak sütür ankor ile artroskopik bankart tamiri, kısa süreli takipte konvansiyonel metal sütür ankor ile karşılaştırılabilir klinik ve fonksiyonel sonuçlar göstermiştir.

Anahtar Kelimeler: Omuz eklemi; artroskopik cerrahi prosedür. 


\section{INTRODUCTION}

Traumatic anterior instability is the most common type of instability in the glenohumeral joint and the most common pathology is antero-inferior labrum lesions (17). Open bankart repair was considered the gold standard procedure in the treatment of traumatic anterior instability; however, arthroscopic repair methods are frequently used recently (2). In addition, the results after the first arthroscopic labrum repair were not at the desired clinical and functional level but improved with the development of anchor and hand tools used in parallel with the developments in technology (8). Conventional metal suture anchors, one of the most commonly used fixation materials in arthroscopic labrum repair, initially cause problems such as loosening, migration, cartilage loss, revision repair difficulty and magnetic resonance imaging as indicated in the literature (10-12). This has increased the tendency to use different detection materials in recent years. New design all-soft sutur anchor that mostly requires drilling a pilot hole into the glenoid bone and then inserting the suture material in a latent configuration connected to a catheter device that allows the suture to expand in the cancellous bone below the cortex when the catheter is removed $(13,14)$. It is facilitate easier revision after surgical failure because they are designed to preserve bone stock and improve post-operative imaging after surgery $(13,15)$. The purpose of this study was to investigate and compare the clinical and functional outcomes of arthroscopic bankart repair with all-soft suture anchor and the conventional metal anchor in physically active patients with a unresponsive to conservative treatment.

\section{MATERIAL AND METHODS}

This retrospective study included 41 consecutive patients who underwent arthroscopic bankart repair by two senior surgeons from October 2016 to December 2017 for a traumatic anterior shoulder instability. A clinical experimental study was carried out in Department of Orthopedic and Traumatology, Duzce University School of Medicine. The study was performed in accordance with the guidelines for declaration of Helsinki-ethical principles for medical research involving human subjects and approved by the Noninvasive-Clinical Ethical Committee of the Medical School of Duzce University, Duzce, Turkey in 2018 (no. 2018/225) and written informed consent was obtained from all patients.

Patients who had isolated bankart lesion confirmed by preoperative magnetic resonance imaging (MRI) at baseline, 18-55 years of age, underwent MRI after surgery at final follow-up, clinical and functional results at baseline, and final follow-up after the operation were included. Patients $<18$ or $>60$ years old, previous shoulder surgery, glenohumeral osteoarthritis, a concomitant lesions (Hill-Sachs, SLAP, posterior labral tear and rotator cuff tear), anterior glenoid bone loss of $>20 \%$, multidirectional instability or generalized joint laxity were excluded. According to these criteria; 9 patients were excluded due to concomitant ipsilateral rotator cuff tear $(n=3)$, patients $<18$ or $>55$ years old $(n=5)$, concomitant ipsilateral anterior glenoid bone loss of $>20 \%(n=1)$.
Demographic data, including the total number of patients, mean age, percentage of male and female patients, mean duration of symptoms, percentage of involvement of the dominant extremity, mean follow-up time, affected side, and number of dislocation or subluxation were recorded.

A total of 32 of these patients who met the eligibility criteria were included in this study. The patients were examined into 2 groups as 17 underwent arthroscopic repair with $1.8 \mathrm{~mm}$ all-suture anchor with 2 (5 metric) Hi$\mathrm{Fi}{ }^{\circledR}$ sutures (Y-knot ${ }^{\circledR}$ flex, Conmed Linvatec, Largo,FL) (group 1), and 15 underwent repair with conventional titanium $3.5 \mathrm{~mm}$ suture anchors with two preloaded ultrabraid sutures (TWINFIX, Smith \& Nephew) (group 2).

\section{Surgical Technique}

All surgeries were performed under general anesthesia in the beach-chair position with a standard posterior, anterior-superior and anterior mid-glenoid portals after the upper extremity was prepared and draped in a standard sterile procedure. Firstly, a diagnostic arthroscopy was made to assess the glenoid labrum, capsule-ligamentous structures, articular surface, biceps tendo, Hill-Scah's lesions and glenoid. Hypertrophic and inflamed synovial tissues were removed by arthroscopic shaver until it had been adequately debrided from anterior-superior and anterior mid-glenoid portal. When anterior labral lesions or capsule-ligamentous structure was diagnosed, a marked probe was introduced into the anterior-superior or anterior mid-glenoid portal to elevate the unstable labrum around the base. The stability and labral continuity of the lesion were determined and also an arthroscopic shaver was used to debride some of the flaps of labrum. The labrum was completely freed from glenoid side and allowed to float freely up to the level of glenoid face. The glenoid bone at the neck was prepared by removing any fibrous tissue. The stabilization of bankart lesion were achieved either by a minimum two $1.8 \mathrm{~mm}$ all-suture anchor with 2 (5 metric) $\mathrm{Hi}-\mathrm{Fi}{ }^{\circledR}$ sutures (Y-knot ${ }^{\circledR}$ flex, Conmed Linvatec, Largo,FL) or with a minimum two conventional titanium $3.5 \mathrm{~mm}$ suture anchors with two preloaded ultrabraid sutures (TWINFIX, Smith \& Nephew). A final evaluation of the joint was done to reveal that the humeral head is balanced in the centre of the glenoid.

\section{Rehabilitation Protocol}

All patients received postoperative therapy based on the same rehabilitation program after surgery. The affected arm was fixed with an abduction sling for 4 weeks at 45 degrees abduction and neutral rotation for 4 weeks. Passive forward flexion, external rotation, and pendulum exercises were started only to the shoulder and elbow joints on postoperative day 3. At the end of week 4, the abduction sling was removed and active exercise was started (e.g., muscle strengthening program for the rotator and deltoid muscles).

\section{Outcome Measurements}

Functional and clinical outcomes were assessed just before the treatment and final follow-up after treatment using the ASES and ROWE score. The ASES score included a physician-rated and patient-rated section; however, only the pain visual analog scale (VAS) and 10 functional questions are typically used to tabulate the reported ASES score. The total score - 100 maximum 
points - is weighted 50\% for pain and 50\% for function. ROWE score is the most commonly reported instability measure. ROWE score assess the three section: stability, function and motion. Motion is evaluated by objective evaluation. Function and motion are scored according to subjective assessment. The total score ranges from 0 (worst) to 100 (best).

\section{Statistical Analysis}

In this study, statistical analysis was done by NCSS (Number Cruncher Statistical System) 2007 Statistical Software (Utah, USA) package program. In the evaluation of the data, percentage and descriptive statistics (mean, standard deviation, median, first and third quartiles) as well as the distribution of variables were analyzed by Shapiro-Wilk normality test. Independent samples t-test and Paired t test were used for comparison of the data with normal distribution, Mann Whitney $U$ test and Wilcoxon test were used for comparison of the non-normal distribution variables, and Chi-square or Fisher's Exact test were used for comparison of qualitative data. A p-value $<0.05$ was considered significant.

\section{RESULTS}

A total of 32 patients who met our eligibility criteria were included; 17 of these patients (14 [82.35\%] males and 3 [17.65\%] females) whose mean age was $33.35 \pm 13.14$ (17-55) years were in group 1 and 15 patients (9 [60\%] males and 6 [40\%] females) whose mean age was $37.47 \pm 11.76$ (18-55) years were in group 2. The right shoulder was affected in 8 (47.06\%), and the left shoulder was affected in 9 (52.94\%) patients in group 1 and the right shoulder was affected in 9 (60\%) and the left shoulder was affected in 6 (40\%) patients in group 2. The mean symptom durations were 11.24 \pm 5.64 (6-24) months in group 1 and $10.93 \pm 5.81$ (6-21) months in group 2. The mean follow-up duration was $23.71 \pm 3.65$ (17-28) months in group 1 and $21.87 \pm 4.39$ (17-28) months in group 2. Preoperatively, 6 (35.29\%) patients had a history of subluxation, 5 (29.41\%) patients had only 1 dislocation, and 6 (35.29\%) patients had 2 or more dislocations in group 1, 6 (40\%) patients had a history of subluxation, 5 (33.33\%) patients had only 1 dislocation, and 4 (26.67\%) patients had 2 or more dislocations in group 2.

No significant difference was observed between mean age, sex, affected side, dominant extremity, mean symptom duration, number of dislocation, mean followup duration of groups 1 and 2 ( $p>0.05$, Table 1$)$.

By the final follow-up, the mean ASES score increased significantly in group 1 from $35.62 \pm 8.46$ to $88.86 \pm 6.23$ $(\mathrm{p}=0.0001)$ and had increased significantly in group 2 from $41.15 \pm 14.51$ to $91.15 \pm 7.54(p=0.0001)$. The mean ROWE score had increased significantly in group 1 from $48.82 \pm 11.25$ to $85.00 \pm 10.00 \quad(p=0.0001)$ and had significantly increased in group 2 from $45.67 \pm 9.61$ to $87.67 \pm 10.15 \quad(p=0.0001)$. There was no significant difference between the mean ASES scores of group 1 and group 2 at pretreatment and final follow-up $(\mathrm{p}=0.192$, $\mathrm{p}=0.353$ ), and also no significant difference between the mean ROWE scores of group 1 and group 2 at pretreatment and final follow-up ( $p=0.404, p=0.461)$. In addition, No significant difference was observed between the mean \% change values of ASES score at the pretreatment- final follow-up in group 1 and group 2 $(\mathrm{p}=0.439)$. And also no significant difference was observed between the mean \% change values of ROWE score at the pretreatment - final follow-up in group 1 and group $2(\mathrm{p}=0.249$, Table 2 , Figure 1$)$.

There were no reported intraoperative, perioperative, or postoperative complications, such as persistent shoulder pain, infection, wound problems, recurrence, stiffness, neurological damage and anchor pull-out.
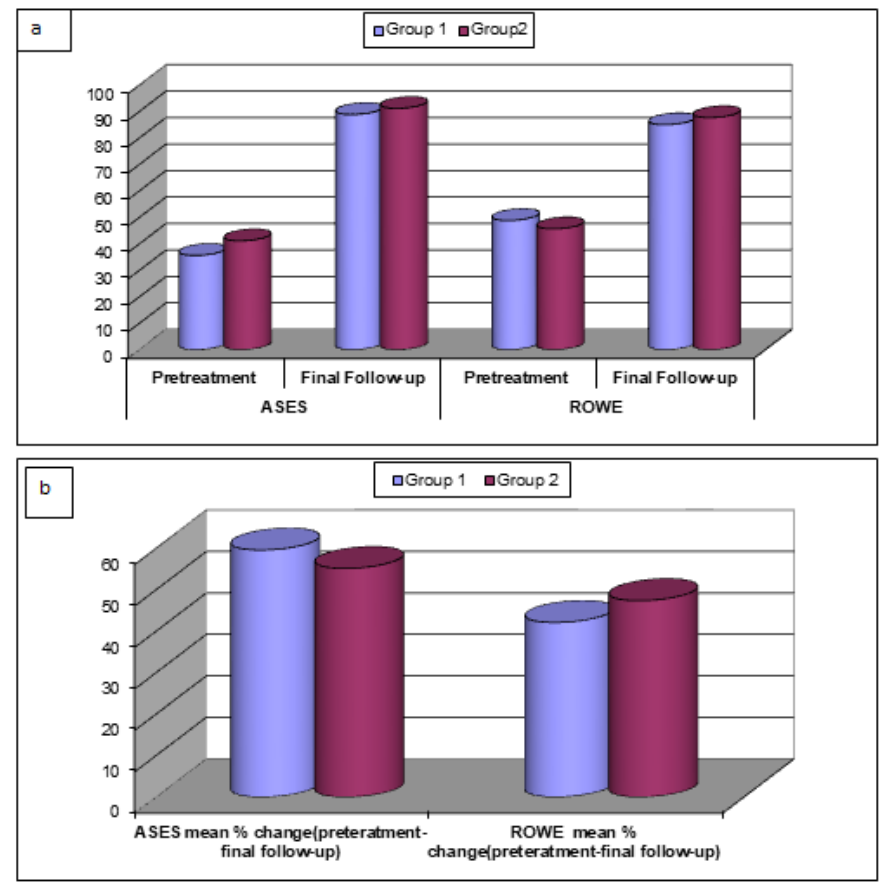

Figure 1a,b. a. Comparison of mean ASES and Rowe score from pretreatment to final follow-up b. Comparison of mean changes ASES and ROWE \% changes score from pretreatment to final follow-up (ASES; American shoulder and elbow surgeons)

\section{DISCUSSION}

Arthroscopic bankart repair has become gold standard treatment options for patients with traumatic anterior shoulder instability $(1,3-5,7,16)$. Several clinical studies have concluded a low rate redislocation and good functional outcomes following arthroscopic anterior stabilization of the shoulder with suture anchors $(2,7,15,16)$. This present study compare the clinical and functional results after arthroscopic bankart repair with all- soft suture anchor and conventional metal anchor in physically active patients with traumatic anterior shoulder instability. By the final follow-up, the mean ASES score increased significantly in both group 1 and group 2 and also the mean ROWE score had increased significantly in both group 1 and group 2. There was no significant difference between the mean ASES scores of group 1 and group and also no significant difference between the mean ROWE scores of group 1 and group 2 at pretreatment and final follow-up. The study indicated that arthroscopic bankart repair is a successful treatment in terms of patient satisfaction, pain relief and functional outcomes at both all- soft suture anchor and conventional metal anchor. 
Over the past three decades, suture anchors (variations in size and suture types, metal or plastic polymer) have been widely used to treat soft tissue pathologies and other musculoskeletal disorders, such as repair of bankart lesions, biceps tenodesis, acromioclavicular joint dislocation reconstruction, deltoid repair and capsulolabral repair (8). However, despite good to excellent outcomes in most studies, there are no gold standard guidelines described for suture anchors use in arthroscopic labral repair (9,16-19). In our experience, the present study demonstrated that arthroscopic labral repair of anterior shoulder instability with this all-soft suture anchors was associated with good clinical and functional outcomes, similar to the conventional suture metal anchor.
Visscher et al. (8) postulated that ideal suture anchor would provide maximise pull out strength, minimise acute iatrogenic damage and minimise long term proarthritic potential. Nagra et al. evaluated the biomechanical properties after all suture anchors compared with conventional anchors. The authors compared 12 fresh-frozen human shoulders that underwent all suture anchors repair to 12 that underwent conventional anchors repair. They demonstrated that decreased failure load, increased total displacement, and variable failure mechanisms in all-suture anchors and also concluded that their findings will aid the surgeons choice of implant, in the context of the clinical scenario (14). In addition, compared to other conventional suture anchors,

Table 1. Summary of patient's demographics and clinical characteristics

\begin{tabular}{|c|c|c|c|c|c|c|}
\hline \multirow{2}{*}{\multicolumn{2}{|c|}{$\begin{array}{c}\text { Age (mean } \pm \text { SD [years]) } \\
\text { Median (Q1-Q3) }\end{array}$}} & \multirow{2}{*}{\multicolumn{2}{|c|}{$\begin{array}{c}\text { Group } 1(\mathbf{n}=\mathbf{1 7}) \\
33.35 \pm 13.14 \\
28(23.5-48.5)\end{array}$}} & \multirow{2}{*}{\multicolumn{2}{|c|}{$\begin{array}{c}\text { Group } 2 \text { (n=15) } \\
37.47 \pm 11.76 \\
37(27-45)\end{array}$}} & $\mathbf{p}$ \\
\hline & & & & & & $0.350^{\ddagger}$ \\
\hline \multirow[b]{2}{*}{ Sex } & Male & 14 & $82.35 \%$ & 9 & $60.00 \%$ & \multirow{2}{*}{$0.243^{++}$} \\
\hline & Female & 3 & $17.65 \%$ & 6 & $40.00 \%$ & \\
\hline \multirow[b]{2}{*}{ Affected side } & Right & 8 & $47.06 \%$ & 9 & $60.00 \%$ & \multirow{2}{*}{$0.464^{+}$} \\
\hline & Left & 9 & $52.94 \%$ & 6 & $40.00 \%$ & \\
\hline \multirow[b]{2}{*}{ Dominant side } & Right & 15 & $88.24 \%$ & 14 & $93.33 \%$ & \multirow{2}{*}{$0.999^{++}$} \\
\hline & Left & 2 & $11.76 \%$ & 1 & $6.67 \%$ & \\
\hline \multirow{3}{*}{$\begin{array}{l}\text { Number of } \\
\text { dislocation }\end{array}$} & Subluctation & 6 & $35.29 \%$ & 6 & $40.00 \%$ & \multirow{3}{*}{$0.911^{++}$} \\
\hline & 1 & 5 & $29.41 \%$ & 5 & $33.33 \%$ & \\
\hline & $\geq 2$ & 6 & $35.29 \%$ & 4 & $26.67 \%$ & \\
\hline \multicolumn{2}{|c|}{$\begin{array}{l}\text { Symptom duration } \\
\text { (mean } \pm \text { SD [months]) } \\
\text { Median (Q1-Q3) }\end{array}$} & \multicolumn{2}{|c|}{$\begin{array}{c}11.23 \pm 5.64 \\
9(7-14)\end{array}$} & \multicolumn{2}{|c|}{$\begin{array}{c}10.93 \pm 5.81 \\
8(7-18)\end{array}$} & $0.737^{\ddagger}$ \\
\hline \multicolumn{2}{|c|}{$\begin{array}{l}\text { Follow-up time } \\
\text { (mean } \pm \text { SD [months]) } \\
\text { (min-max) }\end{array}$} & \multicolumn{2}{|c|}{$\begin{array}{c}23.71 \pm 3.65 \\
(17-28)\end{array}$} & \multicolumn{2}{|c|}{$\begin{array}{c}21.87 \pm 4.39 \\
(17-28)\end{array}$} & $0.206^{*}$ \\
\hline
\end{tabular}

+Chi-Square test, $\neq$ Mann Whitney U test ++Fisher’s Exact, *Independent t test, SD: Standard Deviation, Min: Minimum, Max: Maximum, Q1:1st quartile, Q3: 3rd quartile

Table 2. Comparison of mean ASES -Rowe score and Mean ASES-Rowe \% change from pretreatment and final follow-up

\begin{tabular}{|c|c|c|c|c|}
\hline \multirow[b]{4}{*}{ ASES } & & Group $1(n=17)$ & Group 2 (n=15) & $\mathbf{p}$ \\
\hline & $\begin{array}{l}\text { Pretreatment } \\
(\text { mean } \pm \text { SD) } \\
\text { Median }(\mathrm{Q} 1-\mathrm{Q} 3)\end{array}$ & $\begin{array}{c}35.62 \pm 8.46 \\
33.3(29.2-40.8)\end{array}$ & $\begin{array}{c}41.15 \pm 14.51 \\
35.0(28.3-56.6)\end{array}$ & $0.628^{+}$ \\
\hline & $\begin{array}{l}\text { Final follow-up } \\
(\text { mean } \pm \text { SD) } \\
\text { Median (Q1-Q3) } \\
\end{array}$ & $\begin{array}{c}88.86 \pm 6.23 \\
90.0(85.8-93.3) \\
\end{array}$ & $\begin{array}{c}91.15 \pm 7.54 \\
91.6(88.3-96.6) \\
\end{array}$ & $0.278^{+}$ \\
\hline & $\mathbf{p} \neq$ & 0.0001 & 0.0001 & \\
\hline \multirow[b]{3}{*}{ ROWE } & $\begin{array}{l}\text { Pretreatment } \\
(\text { mean } \pm \text { SD) (min-max) }\end{array}$ & $48.82 \pm 11.25(30-65)$ & $45.67 \pm 9.61(30-60)$ & $0.404^{*}$ \\
\hline & $\begin{array}{l}\text { Final follow-up } \\
\text { (mean } \pm \text { SD) (min-max) }\end{array}$ & $85.00 \pm 10.00(70-100)$ & $87.67 \pm 10.15(70-100)$ & $0.461^{*}$ \\
\hline & $p \neq$ & 0.0001 & 0.0001 & \\
\hline \multicolumn{2}{|c|}{$\begin{array}{l}\text { Mean ASES \% change (Pretreatment } \\
\text { - Final follow-up) } \\
(\text { mean } \pm \text { SD) } \\
\text { Median (Q1-Q3) }\end{array}$} & $\begin{array}{c}59.59 \pm 10.63 \\
61.90(53.58-68.52)\end{array}$ & $\begin{array}{c}55.15 \pm 14.22 \\
62.85(38.40-66.03)\end{array}$ & $0.439^{+}$ \\
\hline \multicolumn{2}{|c|}{$\begin{array}{l}\text { Mean ROWE \% change } \\
\text { (Pretreatment - Final follow-up) }\end{array}$} & & & \\
\hline \multicolumn{2}{|c|}{$\begin{array}{l}\text { (mean } \pm \text { SD) } \\
\text { Median (Q1-Q3) }\end{array}$} & $\begin{array}{c}42.11 \pm 13.92 \\
40(33.30-53.98)\end{array}$ & $\begin{array}{c}47.37 \pm 11.89 \\
45(40.58-58.82)\end{array}$ & $0.249^{+}$ \\
\hline
\end{tabular}

*Independent samples t-test, ‡Wilcoxon test, +Mann Whitney U test, SD: Standard Deviation, Min: Minimum, Max: Maximum, Q1:1st quartile, Q3: 3rd quartile, ASES: American Shoulder and Elbow Surgeon 
the main advantages of this suture anchor are that it provides; facilitate easier revision after surgical failure because they are designed to preserve bone stock and improve post-operative imaging after surgery $(13,15)$.

Similarly, several clinical studies have shown that different suture anchors design for arthroscopic labral lesions produce good to excellent clinical outcomes over short or long-term follow-up $(2,7,15,16)$. For example, Lee et al. performed a comparative prospective randomized controlled single blind study of arthroscopic bankart repair with all-suture anchors and biodegradable suture anchors in patients with recurrent anterior shoulder instability for 2 years follow-up; 33 patients underwent surgery with $1.3 \mathrm{~mm}$ (single loaded) or $1.8 \mathrm{~mm}$ (double loaded) all-suture anchors and another 34 underwent with a $3.0 \mathrm{~mm}$ biodegradable anchor (10.8 $\mathrm{mm}$ in lenght, 30\% 1,2,3- trichloropropane / 70\% poly-lactide-co-glycolide acid). They reported that arthroscopic bankart repair with the all-suture anchor showed comparable clinical outcomes and postoperative stability as the conventional biodegradable suture anchor (15). Another study compared 63 patients treated with nonabsorbable suture anchor and 61 patients who underwent absorbable suture anchor and found that no differences in outcomes of arthroscopic bankart repair were seen whether absorbable or nonabsorbable anchors were used at the 2.6 years follow-up (9). In the present study, despite the short follow-up time (23.71 \pm 3.65 months in group 1 and $21.87 \pm 4.39$ months in group 2), our outcomes were concordant with previously published reports. The mean clinical and functional outcomes after final follow-up showed significant improvements in the ASES and ROWE scores compared to the preoperative status $(p<0.05)$ at both all-soft suture anchors and conventional anchor.

Although arthroscopic surgery suture anchors continue to evolve, the complications of bankart repair have not been completely solved (6,20-23). Metal suture anchor fixation is frequently used although it causes complications such as arthritis, pull-out, and osteolysis $(10,11,14)$. Furthermore, several problems occur with anchor practice in labral repair $(21,22)$. For example, when a retear occurs, revision surgery is sometimes challenging because the previous anchors are difficult to remove with limited room for new anchor insertion. In addition, the cost of multiple anchors is high, and anchor dislodgement and bone osteolysis of glenoid bone $(6,20)$. In this present study on both all-soft suture anchor and conventional metal anchor with arthroscopic labral repair in traumatic anterior shoulder instability, there were no reported intraoperative, perioperative, or postoperative complications, such as persistent shoulder pain, infection, wound problems, recurrence, stiffness, neurological damage, arthritic changes and anchor pull-out.

There were a few limitations to our study. First, it was retrospective and examined relatively short-term outcomes after surgery. In addition, the number of patients was relatively small. Furthermore, despite the relatively low incidence of complications associated with arthroscopic bankart repair in our study, a longer followup may lead to higher complication rates. Further prospective-multicenter studies with large number of patients are needed to optimize the suture anchors design for use during a long-term follow-up.

\section{CONCLUSION}

In this current study, arthroscopic bankart repair with an all-soft suture anchor demonstrated comparable clinical and functional results as the conventional metal suture anchor at short term follow-up. In spite of the improvements in the suture anchors of arthroscopic bankart repair, a gold standard method has not been defined yet and both all-soft suture anchors and conventional metal anchors are still regarded as a good option.

\section{REFERENCES}

1. Saper MG, Milchteim C, Zondervan RL, Andrews JR, Ostrander RV 3rd. Outcomes after Arthroscopic Bankart Repair in Adolescent Athletes Participating in Collision and Contact Sports. Orthop J Sports Med. 2017; 5(3): 2325967117697950.

2. Cole BJ, Warner JJ. Arthroscopic versus open Bankart repair for traumatic anterior shoulder instability. Clin Sports Med. 2000; 19(1): 19-48.

3. Aboalata M, Plath JE, Seppel G, Juretzko J, Vogt S, Imhoff AB. Results of Arthroscopic Bankart Repair for Anterior-Inferior Shoulder Instability at 13-Year Follow-up. Am J Sports Med. 2017; 45(4): 782-7.

4. Fleega BA. Overlap arthroscopic Bankart repair: Reconstruction to the glenoid rim. Arthroscopy. 2002; 18(4): E18.

5. Ee GW, Mohamed S, Tan AH. Long term results of arthroscopic Bankart repair for traumatic anterior shoulder instability. J Orthop Surg Res. 2011; 6: 28.

6. Brown L, Rothermel S, Joshi R, Dhawan A. Recurrent Instability after Arthroscopic Bankart Reconstruction: A Systematic Review of Surgical Technical Factors. Arthroscopy. 2017; 33(11): 208192.

7. Romeo AA, Cohen BS, Carreira DS. Traumatic anterior shoulder instability. Orthop Clin North Am. 2001; 32(3): 399-409.

8. Visscher LE, Jeffery C, Gilmour T, Anderson L, Couzens G. The history of

1. suture anchors in orthopaedic surgery. Clin Biomech (Bristol, Avon). 2019; 61: 70-8.

9. Tan CK, Guisasola I, Machani B, Kemp G, Sinopidis C, Brownson P, et al. Arthroscopic stabilization of the shoulder: A prospective randomized study of absorbable versus non-absorbable suture anchors. Arthroscopy. 2006; 22(7): 716-20.

10. Bek D, Ege T, Erdem Y, Tunay S. Severe cartilage loss caused by metallic anchors in surgical treatment of a Bankart lesion: Report of three cases. Eklem Hastalik Cerrahisi. 2015; 26(2): 116-9.

11. Barber FA, Herbert MA, Hapa O, Rapley JH, Barber CA, Bynum JA et al. Biomechanical analysis of pullout strengths of rotator cuff and glenoid anchors: 2011 update. Arthroscopy. 2011; 27(7): 895-905.

12. Ng DZ, Kumar VP. Arthroscopic Bankart repair using knot-tying versus knotless suture anchors: Is there a difference? Arthroscopy. 2014; 30(4): 422-7.

13. Mazzocca AD, Chowaniec D, Cote MP, Fierra J, Apostolakos J, Nowak M, et al. Biomechanical 
evaluation of classic solid and novel all-soft suture anchors for glenoid labral repair. Arthroscopy. 2012; 28(5): 642-8.

14. Nagra NS, Zargar N, Smith RD, Carr AJ. Mechanical properties of all-suture anchors for rotator cuff repair. Bone Joint Res. 2017; 6(2): 82-9.

15. Lee JH, Itami Y, Hedayati B, Bitner B, McGarry MH, Lee TQ, et al. Biomechanical effects of position and angle of insertion for all-suture anchors in arthroscopic Bankart repair. Clin Biomech (Bristol, Avon). 2018; 60: 45-50.

16. Pötzl W, Witt KA, Hackenberg L, Marquardt B, Steinbeck J. Results of suture anchor repair of anteorior-inferior shoulder instability: A prospective clinical study of 85 shoulders. J Shoulder Elbow Surg. 2003; 12(4): 322-6.

17. Lee JH, Park I, Hyun HS, Kim SW, Shin SJ. Comparison of Clinical Outcomes and Computed Tomography Analysis for Tunnel Diameter after Arthroscopic Bankart Repair with the All-Suture Anchor and the Biodegradable Suture Anchor. Arthroscopy. 2019; 35(5): 1351-8.

18. Lee KH, Soeharno H, Chew CP, Lie D. Arthroscopic Bankart repair augmented by plication of the inferior glenohumeral ligament via horizontal mattress suturing for traumatic shoulder instability. Singapore Med J. 2013; 54(10): 555-9.

19. Hoffmann F. Arthroscopic Bankart operation using absorbable suture anchors. Oper Orthop Traumatol. 2006; 18(2): 101-19.

20. Torrance E, Clarke CJ, Monga P, Funk L, Walton MJ. Recurrence after Arthroscopic Labral Repair for Traumatic Anterior Instability in Adolescent Rugby and Contact Athletes. Am J Sports Med. 2018; 46(12): 2969-74.

21. Randelli P, Ragone V, Carminati S, Cabitza P. Risk factors for recurrence after Bankart repair a systematic review. Knee Surg Sports Traumatol Arthrosc. 2012; 20(11): 2129-38.

22. Barber FA. Complications of Biodegradable Materials: Anchors and Interference Screws. Sports Med Arthrosc Rev. 2015; 23(3): 149-55.

23. Turkmen I, Altun G. Increasing the deltoid muscle volume positively affects functional outcomes after arthroscopic rotator cuff repair. Knee Surg Sports Traumatol Arthrosc. 2019; 27(1): 259-66. 